Check for updates

Cite this: RSC Adv., 2018, 8, 27091

Received 10th May 2018

Accepted 17th July 2018

DOI: $10.1039 / c 8 r a 04006 k$

rsc.li/rsc-advances

\section{New portable smartphone-based PDMS microfluidic kit for the simultaneous colorimetric detection of arsenic and mercury $\dagger$}

\author{
Abbas Motalebizadeh, ${ }^{a}$ Hasan Bagheri, (D) *b Sasan Asiaei, ${ }^{a}$ Nasim Fekrat ${ }^{c}$ \\ and Abbas Afkhami iD d
}

A smartphone-based microfluidic platform was developed for point-of-care (POC) detection using surface plasmon resonance (SPR) of gold nanoparticles (GNPs). The simultaneous colorimetric detection of trace arsenic and mercury ions ( $\mathrm{As}^{3+}$ and $\mathrm{Hg}^{2+}$ ) was performed using a new image processing application (app). To achieve this goal, a microfluidic kit was fabricated using a polydimethylsiloxane (PDMS) substrate with the configuration of two separated sensing regions for the quantitative measurement of the color changes in GNPs to blue/gray. To fabricate the microfluidic kit, a Plexiglas mold was cut using a laser based on the model obtained from AutoCAD and Comsol outputs. The colorimetric signals originated from the formation of nanoparticle aggregates through the interaction of GNPs with dithiothreitol - 10,12pentacosadiynoic acid (DTT-PCDA) and lysine (Lys) in the presence of $\mathrm{As}^{3+}$ and $\mathrm{Hg}^{2+}$ ions. This assembly exhibited the advantages of simplicity, low cost, and high portability along with a low volume of reagents and multiplex detection. Heavy Metals Detector (HMD), as a new app for the RGB reader, was programmed for an Android smartphone to quantify colorimetric analyses. Compared with traditional image processing, this app provided significant improvements in sensitivity, time of analysis, and simplicity because the color intensity is measured through a new normalization equation by converting RGB to an Integer system. As a simple, real-time, and portable analytical kit, the fabricated sensor could detect low concentrations of $\mathrm{As}^{3+}$ (710 to $1278 \mu \mathrm{g} \mathrm{L}^{-1}$ ) and $\mathrm{Hg}^{2+}$ (10.77 to $\left.53.86 \mu \mathrm{g} \mathrm{L}^{-1}\right)$ ions in water samples at ambient conditions.

\section{Introduction}

$\mathrm{As}^{3+}$ is one of the most toxic materials found in the environment. Short-term exposure to $\mathrm{As}^{3+}$ may cause acute and chronic health effects; moreover, long-term exposure to $\mathrm{As}^{3+}$ can cause various cancers including those of skin, lung, urinary bladder, and kidney along with other serious diseases. Consequently, the US Environmental Protection Agency (EPA) and the World Health Organization (WHO) have set the maximum contamination level of $10 \mu \mathrm{g} \mathrm{L}^{-1} \mathrm{As}^{3+}$ in groundwater. ${ }^{1,2} \mathrm{Hg}^{2+}$ is another major environmental pollutant, and it is poisonous in all forms for humans and aquatic systems. $\mathrm{Hg}^{2+}$ causes many complications in the central nervous system, brain, lungs, and kidney; it also causes delayed growth in children when ingested by

${ }^{a}$ School of Mechanical Engineering, Iran University of Science and Technology, Tehran, Iran, 1684613114

${ }^{b}$ Chemical Injuries Research Center, Systems Biology and Poisonings Institute, Baqiyatallah University of Medical Sciences, Tehran, Iran. E-mail: h.bagheri@bmsu. ac.ir; h.bagheri82@gmail.com; Fax: +98 2182482000; Tel: +98 2182482000

${ }^{c}$ Department of Computer, Science and Research Branch, Islamic Azad University, Tehran, Iran

${ }^{d}$ Faculty of Chemistry, Bu-Ali Sina University, Hamedan, Iran

$\dagger$ Electronic supplementary information (ESI) available. See DOI: 10.1039/c8ra04006k pregnant women and damage to the central nervous system. ${ }^{3,4}$ Thus, the WHO and US EPA have set the maximum permissible levels of $\mathrm{Hg}^{2+}$ in drinking water as 6 and $2 \mu \mathrm{g} \mathrm{L}^{-1}$, respectively.,

Several methods have been reported for the individual/ simultaneous determination of $\mathrm{As}^{3+}$ and $\mathrm{Hg}^{2+}$ including atomic fluorescence spectrometry (AFS), ${ }^{\mathbf{5} 6}$ atomic absorption spectrometry (AAS), ${ }^{7,8}$ electrochemical methods, ${ }^{\mathbf{9 , 1 0}}$ and inductively coupled plasma-atomic emission spectrometry (ICP-AES). ${ }^{\mathbf{1 1}, \mathbf{1 2}}$ Although these methods provide high sensitivity and selectivity, they require trained users, complicated instruments, and a long analysis time, which make them unsuitable for POC detection.

In recent years, smartphones have been designed with many remarkable features, due to which they provide a promising digital platform for POC diagnostics. ${ }^{13}$ This rapid, simple, portable, ubiquitously available and cost-effective technology enables minimally trained users to perform chemical analyses in the field..$^{\mathbf{1 4 1 5}}$ Smartphones are widely used in sensors such as rapid test strips, sensor chips, and hand-held detectors for detecting heavy metals. ${ }^{13,16,17}$ Compared with classical configurations integrated with smartphone detection, which involve complex prism integration, metal nanoparticles are simply adapted for use in portable devices to achieve POC applications. $^{18}$ 


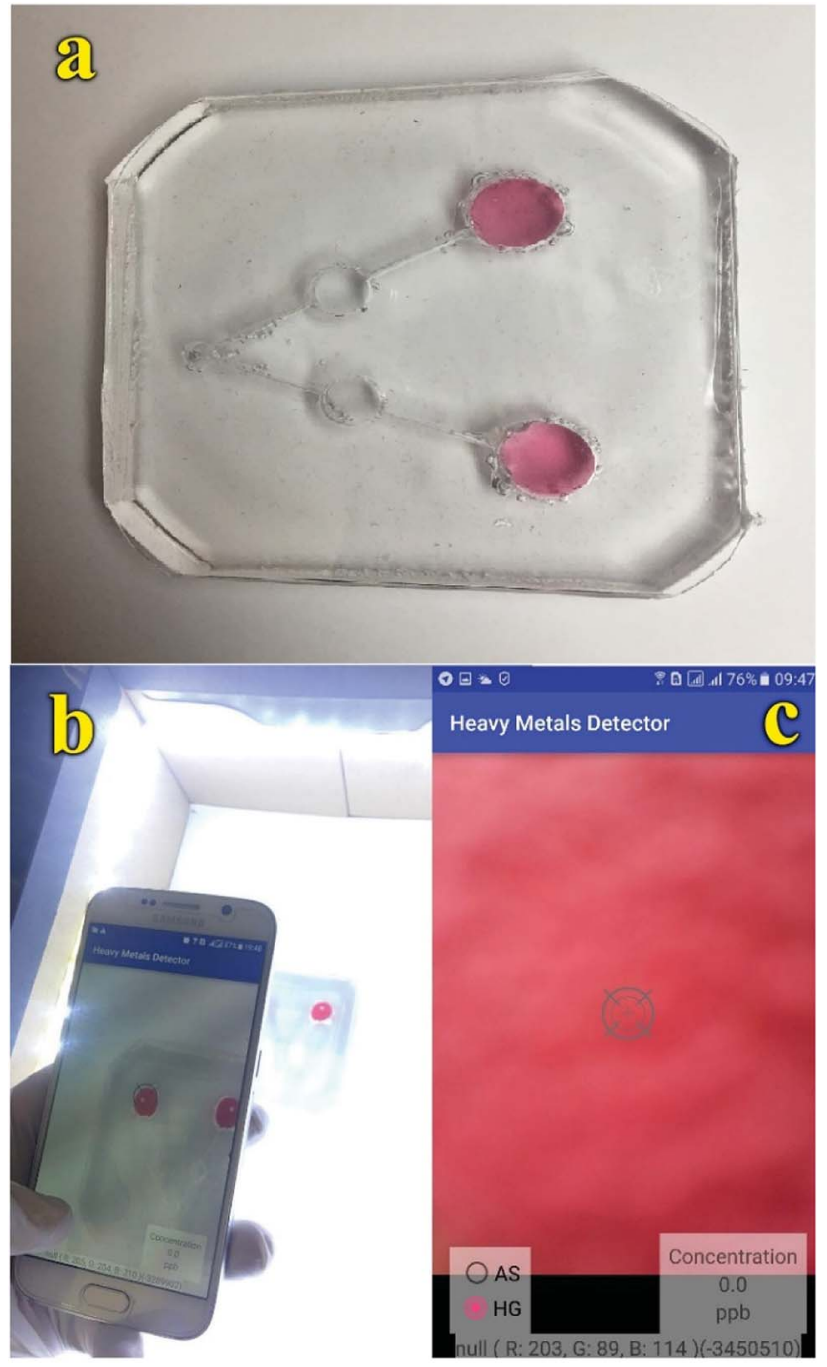

Fig. 1 (a) Fabricated microfluidic kit, (b) imaging platform using a smartphone and (c) HMD mobile application.

Among these metal nanoparticles, GNPs have been widely used as colorimetric probes for the detection of heavy metal ions to provide alternative techniques to conventional detection methods. ${ }^{19,20}$ In a typical GNP-based colorimetric assay, depending on the size, GNPs are red-/purple-colored and change to gray/ blue in the presence of certain analytes through aggregation (analyte-induced) or disaggregation (dispersion). These properties provide a speedy and convenient strategy to develop colorimetric assays for the measurement of the desired analytes. ${ }^{19-21}$ It should be mentioned that many successful colorimetric probes have been reported for the detection of single heavy metal ions including $\mathrm{Hg}^{2+}, \mathrm{Pb}^{2+},{ }^{23} \mathrm{Cr}^{3+},{ }^{24} \mathrm{Mn}^{2+},{ }^{25}$ and $\mathrm{Cu}^{2+}$ (ref. 30) ions.

However, colorimetric sensor arrays capable of heavy metal ion multiplex detection are scarcely reported, which may be due to lack of selectivity between metal ions for their simultaneous colorimetric detections. ${ }^{25-29}$ Motivated by these clear demands, we attempted to take advantage of the microfluidic systems. Microfluidic devices have provided great opportunities as they are simple, low-cost, and present rapid analysis; they also provide highly portable analysis by using low volumes of reagent along with the possibility of multiplex detection for analytical applications. $^{31,32}$ Therefore, some microfluidic devices have been developed based on PDMS and paper for the detection of heavy metals such as $\mathrm{Hg}^{2+}, 33 \mathrm{~Pb}^{2+}, 34$ and $\mathrm{Cr}^{3+}$ (ref. 35) ions. Herein, we have developed a new smartphone-based colorimetric system using the plasmonic resonance property of GNPs in a dualmicrochannel PDMS kit in a microfluidic device for the simultaneous trace detection of $\mathrm{As}^{3+}$ and $\mathrm{Hg}^{2+}$ ions. The quantitative colorimetric analysis is performed using accessible Galaxy S6 in which we installed the HMD app (Fig. 1). Also, the steps for the fabrication of the microfluidic kit are shown in Fig. S1.† Finally, the proposed colorimetric kit is employed to evaluate its applicability in the simultaneous determination of $\mathrm{As}^{3+}$ and $\mathrm{Hg}^{2+}$ ions in water sources as the pollution caused by these ions can be responsible for serious threats to human health.

\section{Experimental}

\section{Chemicals and materials}

All chemicals were purchased from Merck (Darmstadt, Germany). Sodium citrate tribasic dihydrate, gold(III) chloride trihydrate, Lys, DTT, L-glutathione (GSH), L-cysteine, $\mathrm{KCl}, \mathrm{SnCl}_{2}$, $\mathrm{ZnCl}_{2}, \mathrm{~Pb}\left(\mathrm{NO}_{3}\right)_{2}, \mathrm{HgCl}_{2}, \mathrm{AlCl}_{3}, \mathrm{As}_{2} \mathrm{O}_{3}, \mathrm{Na}_{3} \mathrm{PO}_{4}, \mathrm{Na}_{2} \mathrm{SO}_{4}, \mathrm{NaNO}_{3}$, $\mathrm{Na}_{2} \mathrm{CO}_{3}, \mathrm{Na}_{3} \mathrm{PO}_{4}, \mathrm{KBr}, \mathrm{NaAc}, \mathrm{KClO}_{4}, \mathrm{PDMS}$, phosphate salts $\left(\mathrm{KH}_{2} \mathrm{PO}_{4}\right.$ and $\left.\mathrm{K}_{2} \mathrm{HPO}_{4}\right), \mathrm{NaOH}$, and $\mathrm{HCl}$ were used as received without further purification. Deionized water (DI) was used to prepare all solutions. Plexiglas and glass wafers were also purchased from a local market.

\section{Instruments}

In this study, the smartphone used was a Samsung Galaxy S6, which has an S800 CPU and a $13 \mathrm{M}$ pixel camera. It enables image processing in real-time, and the high-resolution camera produces finely digitized images. A Varian Cary 100 UV-vis spectrophotometer (Varian Inc., Canterbury, Australia) was used to measure the absorption of colloidal GNP-based solutions. The size, shape, and distribution of GNPs were determined via transmission electron microscopy (TEM, Zeiss Libra 200, Zeiss Oberkochen, Germany). A digital pH-meter (Cyberscan 2100) was employed for $\mathrm{pH}$ measurements. The solutions were stirred using a Heidolph MR $3001 \mathrm{~K}$ magnetic stirrer (Schwa Bach, Germany). The Plexiglas was cut using Universal Laser Systems VLS2.30 (Scottsdale, U.S.). Oxygen plasma treatment of the PDMS surfaces was accomplished at $150 \mathrm{~W}$ and 400 mTorr oxygen pressure for 30 seconds using a plasma asher (Model PE II-A, Technics West Inc.).

\section{Synthesis of GNPs and modification of GNPs with DTT}

Unmodified GNPs were prepared in accordance with the procedure given in the literature ${ }^{36}$ (explained in the $\operatorname{ESI}_{\dagger} \dagger$ ). Aqueous solutions of GNPs $(1.5 \mathrm{nM})$ and DTT $(10 \mathrm{mM})$ were mixed in different concentration ratios. The mixtures were allowed to react for 1.0 to $5.0 \mathrm{~min}$ at room temperature in the dark with continuous stirring to ensure self-assembly of DTT onto the surface of GNPs. 


\section{Fabrication of PDMS microfluidic kit}

The mold for the fabrication of the microfluidic kit designed in AutoCAD ${ }^{\circledR}$ and Plexiglas was cut using Laser Systems. Using laser cutting, a mold with the desired shape was designed to develop a two-sensing region. The step-by-step fabrication of the microfluidic device is shown in Fig. S1. $\dagger$ In this configuration, the radii of the inlet, Reservoirs 1 and 3, and Reservoirs 2 and 4 were 2,4 , and $6 \mathrm{~mm}$, respectively. In addition, the width and depth (equal to the depth of the inlet) of all the microchannels were $500 \mu \mathrm{m}$ and $1 \mathrm{~mm}$, respectively (Scheme 1). Also, a $3 \times 3 \mathrm{inch}^{2}$ glass substrate was fixed to the top of a dry PDMS chip by oxygen-plasma treatment.

A glass wafer was used as a mold substrate for the replication of the microchannel pattern in PDMS. The fabrication steps are briefly described as follows. First, the wafer was attached to the mold using chloroform; to de-gas PDMS, it was kept at $4{ }^{\circ} \mathrm{C}$ in a refrigerator for five hours. The usual PDMS baking protocol $\left(150{ }^{\circ} \mathrm{C}\right.$ for 10 minutes or $100{ }^{\circ} \mathrm{C}$ for 45 minutes) was modified to avoid high temperatures and preserve the Plexiglas substrate. ${ }^{37}$ Therefore, for cooking, the initial temperature was set in the range from $100{ }^{\circ} \mathrm{C}$ to $125{ }^{\circ} \mathrm{C}$ for 10 minutes in such a way that every 2 minutes, the temperature rose by $5{ }^{\circ} \mathrm{C}$. Then, the system was heated at $125^{\circ} \mathrm{C}$ for 4 minutes. Thereafter, the temperature increased from $125{ }^{\circ} \mathrm{C}$ to $135{ }^{\circ} \mathrm{C}$ for 4 minutes, and it was maintained at $135{ }^{\circ} \mathrm{C}$ for 5 minutes. In the next step, the temperature was reduced from $135{ }^{\circ} \mathrm{C}$ to $100{ }^{\circ} \mathrm{C}$ at $7{ }^{\circ} \mathrm{C}$ per minute, and it was allowed to reach room temperature.

For the fabrication of the kit, the kit was washed with $800 \mu \mathrm{L}$ water to remove potential contaminants. Before the

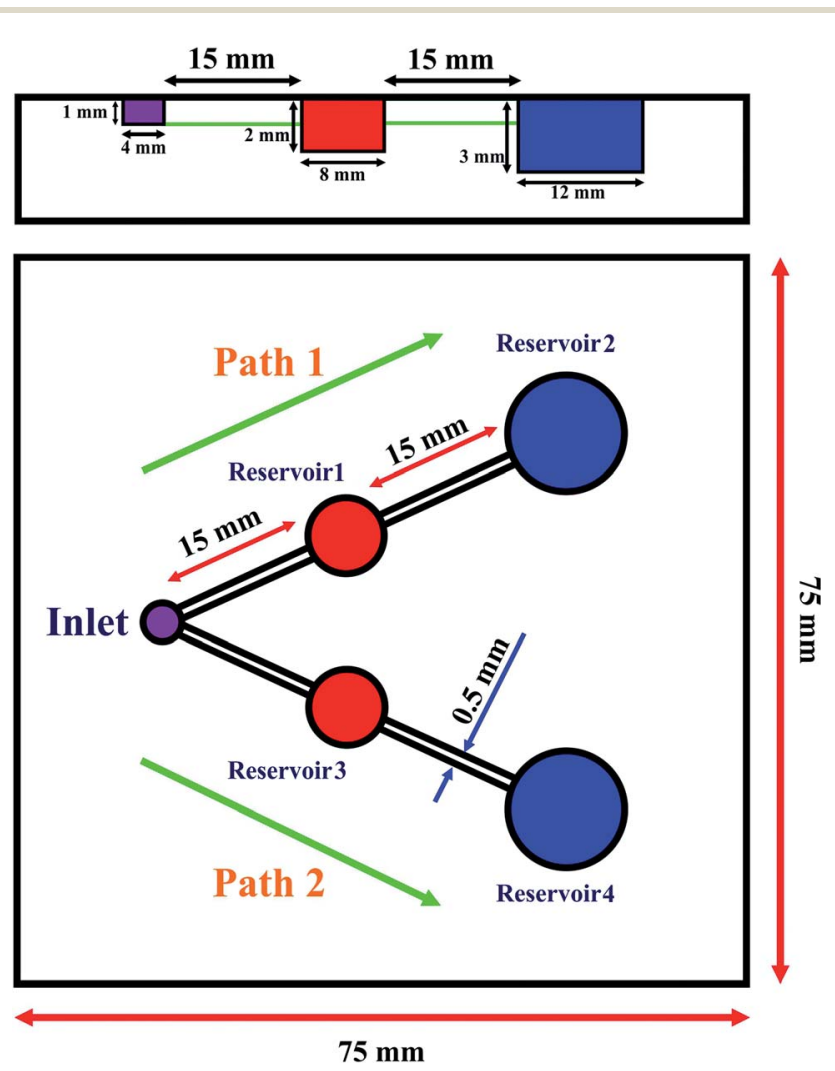

Scheme 1 Design of the microfluidic kit. experiments, the reagent solutions of GNPs-DTT and GNPs were introduced into Reservoirs 2 and 4, respectively; phosphate buffer solution (PBS) of pH 8.5 and Lys were introduced in Reservoirs 1 and 3, respectively. In the following step, the surface of PDMS was exposed to the corona. Subsequently, the design was completed by attaching a glass with two holes in the inlet and Reservoirs 2 and 4 . When the sample solution $(410 \mu \mathrm{L})$ containing $\mathrm{As}^{3+}$ and $\mathrm{Hg}^{2+}$ ions was injected into the inlet, the fluid started flowing into Path no. 1 and no. 2 through the microchannels by capillary action, as shown in Scheme 1. In Path 1 , the sample $(205 \mu \mathrm{L})$ first passed microchannel 1 and then, it was introduced into Reservoir 2; next, it mixed with the stored PBS having $\mathrm{pH} 8.5(45 \mu \mathrm{L})$. The sample ( $\mathrm{pH}$ 8.5) then moved through Microchannel 2 and reached Reservoir 3. Here, the $\mathrm{As}^{3+}$ ions in the sample interacted with the previously stored GNPs-DDT complexes $(90 \mu \mathrm{L})$ in Reservoir 3, resulting in aggregation and change in the color of GNPs from red to blue/ gray. Also, when the sample solution $(205 \mu \mathrm{L})$ was introduced into Path no. 2, it first moved toward Reservoir 3 containing Lys $(27 \mu \mathrm{L})$ through Microchannel 3. Next, the sample containing Lys and $\mathrm{Hg}^{2+}$ ions moved to Reservoir 3 via microchannel 4 and reacted with the previously embedded GNPs $(108 \mu \mathrm{L})$ to form GNPs-Lys-Hg aggregates. These color changes were processed using the developed imaging system to determine $\mathrm{Hg}^{2+}$ and $\mathrm{As}^{3+}$ contents in the samples.

\section{Smartphone platform setup and colorimetric analysis}

A portable platform was designed to assist the camera of the smartphone at the top of the platform to capture uniform images for colorimetric sensing. White LEDs were used on the walls of the detection box to illuminate the sample area and eliminate the interference of light from the region besides the sensing area. The sample was injected into the kit inlet, which was divided into two separated paths for the simultaneous determination of target analytes. The whole surface of the microfluidic kit was covered by a piece of glass slide containing two holes on the top of the inlet and Reservoirs 2 and 4, which provided a place for injecting the sample and reagent solutions. The smartphone was placed at the top of the test zone horizontally in the $X-Y-Z$ space in such a way that the height of the smartphone could also be adjustable to fit the focal length. The images taken from the smartphone showed a color change to less reddish (more blue/gray) with an increase in the concentration of target analytes. In addition, a new RGB color reader app was used to convert RGBs to changes in color intensity using integers.

\section{Results and discussion}

\section{Structure and morphology characterization}

To perform the TEM analysis, six different samples were prepared by depositing a drop of sample solution on a carboncoated $\mathrm{Cu}$ grid (3 $\mathrm{mm}$ diameter) and drying at room temperature. The morphologies of bare GNPs, ligand-modified GNPs, and modified GNPs in the presence of $\mathrm{As}^{3+}$ and $\mathrm{Hg}^{2+}$ ions were investigated via TEM (Fig. 2). The mean diameters, diameter 
size frequency in the samples, and the corresponding histograms were obtained using the Stratigraphic Plus software (Fig. S2 $\dagger$ ). The smallest particles (mainly spherically shaped) with a mean size of $18 \mathrm{~nm}$ and small size dispersion were obtained for bare GNPs. However, after modification, the size of the particles increased. The TEM images showed that the GNPs modified with DTT and Lys presented a larger mean particle size and size distribution ( $25 \mathrm{~nm})$. Finally, in the presence of analytes, it was observed that the shape of the particles was not spherical, and the complexation of $\mathrm{As}^{3+}$ and $\mathrm{Hg}^{2+}$ ions resulted in the aggregation and enlargement of the modified GNPs. This indicated that $\mathrm{As}^{3+}$ and $\mathrm{Hg}^{2+}$ ions bind with GNPs-DTT and GNPs-Lys, respectively, to form aggregates in solution., ${ }^{4,34}$

To explore the affinity of the GNP-based sensor toward $\mathrm{As}^{3+}$ and $\mathrm{Hg}^{2+}$ ions, the UV-vis technique was also utilized to monitor the color change in the kit. The insets of Fig. 2 summarize the UV-vis spectra of GNPs in different solutions. Prior to interacting with $\mathrm{As}^{3+}$ and $\mathrm{Hg}^{2+}$ ions, non-functionalized and functionalized GNPs were reddish in color and possessed a strong absorption band located at $519 \mathrm{~nm}$. Upon the addition of $\mathrm{As}^{3+}$ and $\mathrm{Hg}^{2+}$ ions to the corresponding GNP-modified ligand, a distinct color change in the GNPs from red to blue/gray was observed at concentrations of $710 \mu \mathrm{g} \mathrm{L}^{-1}$ and $20 \mu \mathrm{g} \mathrm{L}^{-1}$ for $\mathrm{As}^{3+}$ and $\mathrm{Hg}^{2+}$ ions, respectively. The corresponding UV-vis spectra showed a broad and strong shift in the plasmon absorption peak to a higher wavelength $\left(682 \mathrm{~nm}\right.$ and $642 \mathrm{~nm}$ for $\mathrm{As}^{3+}$ and $\mathrm{Hg}^{2+}$, respectively), which can be due to particle agglomeration. These observations can be explained by the interactions between the S-groups in DTT and the $\mathrm{As}^{3+}$ ions and N-groups of Lys and $\mathrm{Hg}^{2+}$ ions. ${ }^{4,38}$

\section{Microfluidic development}

Microchannel fabrication. The configuration of the microfluidic network is shown in Scheme 1 and Fig. S1. $\dagger$ Because of the low Reynolds numbers, $\mathrm{Re}_{2} \mathrm{~h},{ }^{39,40}$ laminar flow was expected in the network ( $6.6>\mathrm{Re})$. Negligible electrical force was assumed, and gravity could be ignored because of the relatively small height of the microchannel and the use of isotropic, dilute solutions. Moreover, the temperature variations in the mass transport and chemical reactions were not significant. ${ }^{\mathbf{4 1 , 4 2}}$ The inlet received a net constant fluid velocity, which is represented here by a constant cross-sectional average velocity: $U$. The outlets experienced atmospheric pressure as a small hole was drilled on the top, and no-slip was assumed at the walls. The fluid was assumed to be driven by the sampler, exerting an appropriate pressure difference across the two ends of the microchannel network. To properly model the chemical reaction, it is necessary to investigate the flow of the sample in the proposed kit. Thus, Comsol Multiphysics was used to couple and study the fluidic (diffusion/convention) and chemical reactions in the microchannels. The major parameter that has to be determined is the concentration of the reactant and consequently, the reaction progress rate. For this aim, the velocity field across the whole channel should be determined in real time. The sample flows in a variable geometry; thus, it is more convenient to use the tensor form of the momentum and continuum equations along with the

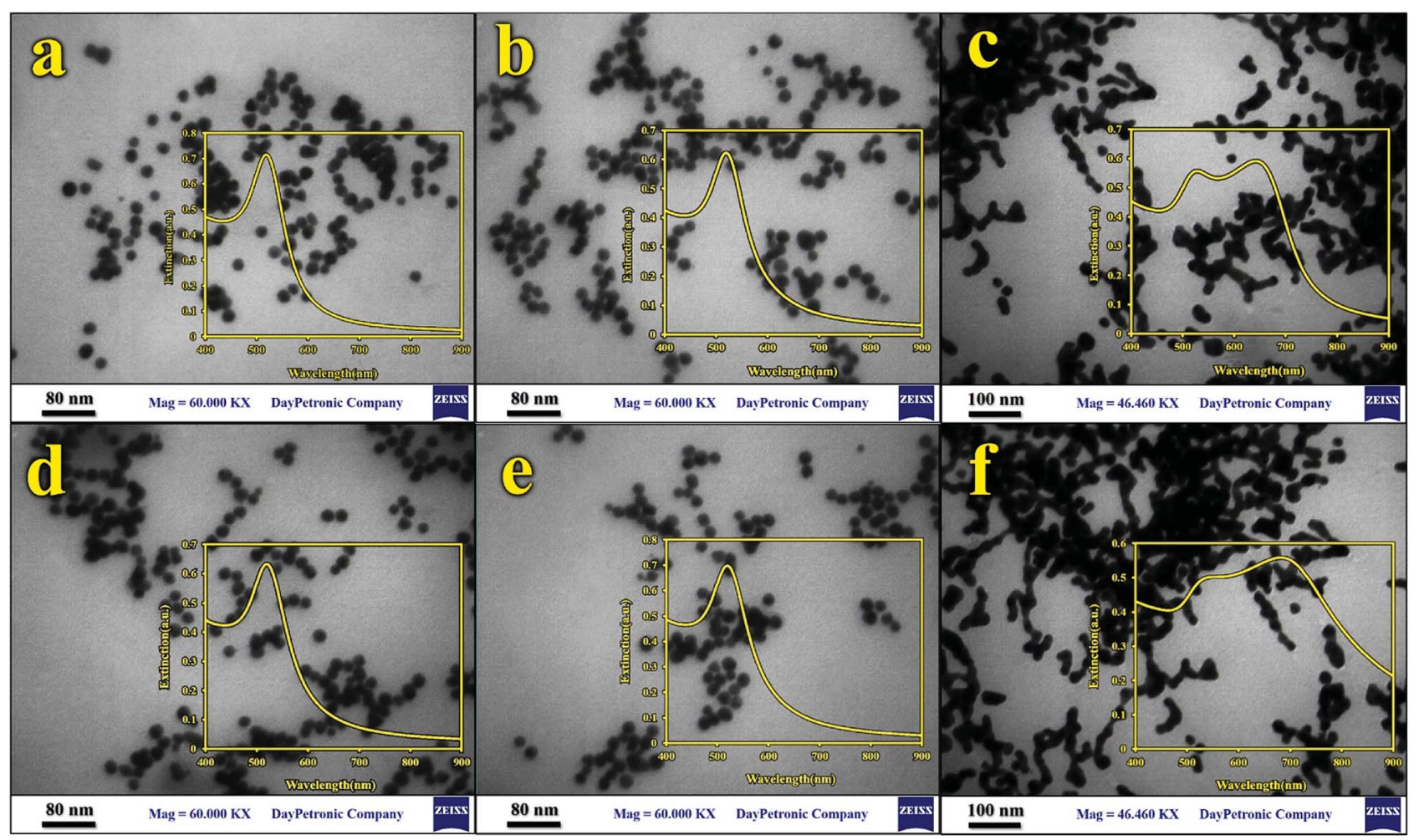

Fig. 2 TEM images and UV spectra of (a) GNPs, (b) GNPs-Lys, (c) GNPs-Lys-Hg ${ }^{2+}$ ions, (d) GNPs-DTT, (e) GNPs-DTT-PCDA, and (f) GNPsDTT-PCDA As ${ }^{3+}$ ions. 
fluid-structure interaction (FSI) equation to account for the fluid Frontier interaction with the PDMS walls. ${ }^{\mathbf{4 3 4 4}}$ A longitudinal section along with the middle of the connecting microchannels was assumed, and the variation in the average sectional velocity was measured. Upon injection of the water sample into the inlet, the average velocity increased from zero to $0.01 \mathrm{~ms}^{-1}$. Owing to the contraction of the cross-sectional area, the velocity increased in the connecting channel and then decreased upon entry into Reservoirs 1 and 3. The sample then flowed to the last reservoirs (2 and 4). The water sample was injected into the inlet chamber, and the injection was continued until the water reached and filled the last reservoirs ( 2 and 4 ). Based on calculations and the experimental results of the chemical processes, we inferred that the fluid entered the connecting channels with a cross-sectional average velocity of $10 \mathrm{~ms}^{-1}$.

The volume of the engraved microchannels and reservoirs is equal to the sum of the sample volume (injected solution), the embedded nanoparticle solution, and the Lys solution. The embedded reagents in the reservoirs eliminate the need for any pre- or post-processing of the chemical reactions, enabling portable usage in low resourceful environments.

Numerical simulations. For rapid and accurate quantification of ions, Android Studio was used, and a Java HMD App was developed. The RGB parameters were analyzed and compared with a standard database trained by standard sample concentrations. We designed a special algorithm to convert the intensity of the three traits of RGB, i.e., red, green, and blue to concentrations of ions $\left(\mathrm{As}^{3+}\right.$ and $\left.\mathrm{Hg}^{2+}\right)$. There are various methods to convert RGBs in an Android environment to a unit number, and we selected the Integer method, which has greater sensitivity to red color, provided that the basic color of GNPs is red. This was confirmed by an intense change in $R$ values by measuring standard sample concentrations. ${ }^{4-48}$ The developed app could quantify the two ions $\mathrm{Hg}^{2+}$ and $\mathrm{As}^{3+}$ up to parts per billion and million ( $\mu \mathrm{g} \mathrm{L}^{-1}$ or $\mathrm{mg} \mathrm{L}^{-1}$ ), respectively. The effect of environmental light intensity on the sensitivity and quantification accuracy was also eliminated. A training algorithm was run on the software; by measuring samples under standardized environmental light intensities, a sufficiently large data table was created. As a result, the peripheral light effect on the sample was canceled through a comparison with the light intensity data table.

$$
\begin{gathered}
\rho \frac{\partial u}{\partial t}+\rho(u \cdot \nabla) u=\nabla\left[-\rho l+\mu\left(\nabla u+(\nabla u)^{T}\right)-\frac{2}{3} \mu(\nabla \cdot u) l\right]=F \\
\frac{\partial \rho}{\partial t}+\nabla(\rho u)=0 \\
\rho \frac{\partial^{2} u}{\partial t^{2}}-\nabla \cdot \sigma=F
\end{gathered}
$$

\section{Colorimetric behavior of modified GNPs}

Sensing mechanism of our probe for $\mathrm{As}^{3+}$ and $\mathbf{H g}^{2+}$ ions. The as-prepared DTT-GNPs are stable because DTT protects GNPs from aggregation in the presence of a certain high concentration of sodium chloride. DTT has two - $\mathrm{SH}$ groups to provide a strong interface between GNPs and $\mathrm{As}^{3+}$ ions. Thus, DTT can capture $\mathrm{As}^{3+}$ ions in aqueous solution, resulting in the aggregation of GNPs. As shown in Scheme 2a, the aggregation of DTT-GNPs in the presence of $\mathrm{As}^{3+}$ ions yields a substantial shift in the plasmon band energy to a longer wavelength and a red-toblue/gray color change. Although in the previous method reported by Chandra Ray and coworkers, ${ }^{38}$ the detection method for $\mathrm{As}^{3+}$ ions was based on the aggregation of GSH/DTT/Cysmodified GNPs, in our experiments, it was observed that DTT-GNPs alone exhibited more sensitive responses in comparison with those by GSH/DTT/Cys-modified GNPs. ${ }^{38}$ This can be explained by the fact that $\mathrm{As}^{3+}$ ions have a very high affinity for ligands containing sulfur groups compared to that for the - $\mathrm{COOH}$ groups in GSH and Cys. Also, the non-specific bonding of $\mathrm{As}^{3+}$ ions with undesired polar groups in GSH and Cys, reduction in the mobility of GNPs and/or spatial hindrance of these ligands may reduce invaluable interactions to catalyze GNP aggregations.

Furthermore, Scheme $2 \mathrm{~b}$ shows the proposed $\mathrm{Hg}^{2+}$ sensing mechanism of the colorimetric assay, which is different from that of $\mathrm{As}^{3+}$. According to the synthesis method of GNPs, the surface of the synthesized GNPs is covered with citrate ions, which interact with $\mathrm{Hg}^{2+}$ ions upon the addition of $\mathrm{Hg}^{2+}$ solution to the GNP solution. ${ }^{36}$ According to the literature, $\mathrm{Hg}^{2+}$ ions can simultaneously react with the GNP surface to form an $\mathrm{Hg}^{2+}$ layer with positive charges. When Lys is added to the $\mathrm{Hg}^{2+}$ interacted GNPs, the color of the GNP suspension immediately changes from red to blue/gray due to the aggregation of GNPs. ${ }^{4}$

Influence of DTT and Lys concentration. To investigate the effect of DTT concentration on the proposed kit, six different concentrations of DTT ranging from 0 to $0.52 \mathrm{mM}$ were tested at 20 minute intervals in the presence and absence of $\mathrm{As}^{3+}$ ions for control experiments (Fig. S3†). According to the experiments in the absence of $\mathrm{As}^{3+}$ ions in $20 \mathrm{~min}$, there was no color intensity change as the DTT concentration increased. However, DTTmodified GNPs aggregated after the addition of $\mathrm{As}^{3+}$ ions. The results also showed that with an increase in DTT concentration, the color intensities decreased in all time intervals. The lowest concentration with the maximum color change was $0.43 \mathrm{mM}$ (8.0 min). Additionally, the influence of binding time for the reaction between GNPs and DTT was studied and optimized in the range from 1.0 to 5.0 min under stirring at a speed of $160 \mathrm{rpm}$. It was observed that the color intensities remained constant for all the time intervals investigated at an $\mathrm{As}^{3+}$ concentration of $710 \mu \mathrm{g} \mathrm{L}^{-1}$. Therefore, the optimal time for the preparation of DTT-modified GNPs was considered to be 1.0 minute at a DTT concentration of $0.43 \mathrm{mM}$ for subsequent studies. This short reaction time is probably caused by the high affinity of -SH groups in the DTT structure for GNPs. ${ }^{37,38,49,50}$

In the next experiment, the effect of Lys concentration on the signal intensity was investigated in the range from 0.0 to $11.33 \mathrm{mM}$ before and after addition of $\mathrm{Hg}^{2+}$ ions in a $6.0 \mathrm{~min}$ time interval. In the absence of $\mathrm{Hg}^{2+}$, it was found that the signal intensities remained stable at concentrations lower than 8.3 $\mathrm{mM}$, followed by decrease in signal intensities at Lys concentrations higher than $8.3 \mathrm{mM}$. These results indicated 

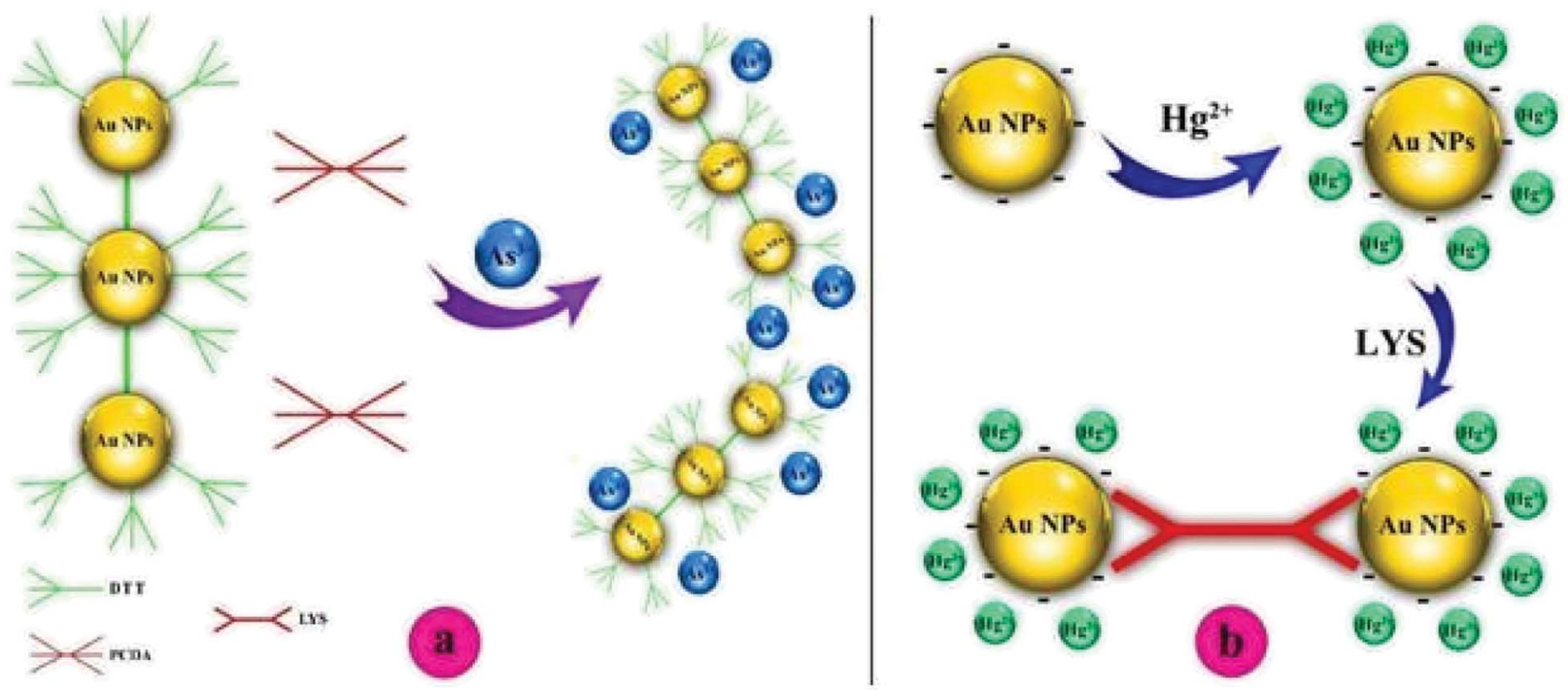

Scheme 2 Proposed (a) $\mathrm{As}^{3+}$ and (b) $\mathrm{Hg}^{2+}$ sensing mechanisms of the colorimetric assay.

that at a high concentration of Lys, negative-charged citratecaped GNPs can interact with the polar groups on the Lys structure via ion-hydrogen bonding interactions, leading to aggregation. In addition, the signal intensities decreased from 7.0 to 5.0 as the detection time increased from 1 to 6 minutes. Also, in the presence of $\mathrm{Hg}^{2+}$ ions, the results showed that the signal intensities did not change with a Lys concentration of $6 \mathrm{mM}$ at the beginning of the reaction; however, at higher concentrations, the signal intensities started decreasing at the beginning of $\mathrm{Hg}^{2+}$ addition at a concentration of $20 \mu \mathrm{g} \mathrm{L}^{-1}(0$ minute). $\mathrm{Hg}^{2+}$ can be seen in Fig. S3; $\dagger$ however, when the time of the reaction increased from 0 to 6 minutes, the signal intensities decreased dramatically at all concentrations of Lys. Finally, the concentration of $3 \mathrm{mM}$ was selected as the optimum value because the maximum response was obtained at a short reaction time for $\mathrm{Hg}^{2+}$ detection.

\section{Effect of pH}

The as-prepared GNPs are stable because of electrostatic repulsion against van der Waals attraction of the negative capping agent, i.e., citrate. Therefore, a change in the $\mathrm{pH}$ value may affect the electrostatic repulsion between the unmodified negatively charged GNPs and lead to their aggregation. Therefore, the influence of $\mathrm{pH}$ on the colorimetric responses of GNPs-DTT and GNPs-Lys was studied at different $\mathrm{pH}$ values in the presence and absence of $\mathrm{As}^{3+}$ and $\mathrm{Hg}^{2+}$ ions. For $\mathrm{As}^{3+}$ detection, the $\mathrm{pH}$ of the solution was investigated in the range from 7.5 to 10.5 based on the signal intensities using PBS because GNPs aggregated at lower $\mathrm{pH}$ values. This can be probably because of the isoelectric point of GNPs. In the presence of $\mathrm{As}^{3+}$ ions $\left(710 \mu \mathrm{g} \mathrm{L}^{-1}\right)$, a sharp decrease in the signal intensity was observed in the $\mathrm{pH}$ range from 7.5 to 8.5, which was followed by an increase in intensity in the range from 8.5 to 10 .

Next, a sharp decrease in the signal intensity was observed as the $\mathrm{pH}$ value increased from 10 to 10.5 in the 10 minute analysis time. Therefore, $\mathrm{pH}$ of 8.5 was selected as the optimum value for subsequent experiments (Fig. 3).

Depending on $\mathrm{pH}$, there are four different forms of $\mathrm{As}(\mathrm{III})$ and $\mathrm{As}(\mathrm{v}): \mathrm{H}_{3} \mathrm{AsO}_{3}, \mathrm{H}_{2} \mathrm{AsO}_{3}{ }^{-}, \mathrm{HAsO}_{3}{ }^{2-}$, and $\mathrm{AsO}_{3}{ }^{3-}$ vs. $\mathrm{H}_{3} \mathrm{AsO}_{4}$, $\mathrm{H}_{2} \mathrm{AsO}_{4}{ }^{-}, \mathrm{HA}_{5} \mathrm{O}_{4}{ }^{2-}$, and $\mathrm{AsO}_{4}{ }^{3-}$. $\mathrm{As}(\mathrm{III})$ is uncharged at neutral $\mathrm{pH}$, whereas $\mathrm{As}(\mathrm{v})$ is negatively charged. ${ }^{48}$ According to the literature, at the experimental $\mathrm{pH}$ value of 8.5 , arsenite is in the form of $\mathrm{H}_{2} \mathrm{AsO}_{3}{ }^{-} / \mathrm{H}_{3} \mathrm{AsO}_{3}$ and contains two/three hydroxyl groups $(-\mathrm{OH})$, due to which they can easily bind to DTT via hydrogen bonds as the -SH functional group is kept free for $\mathrm{As}^{3+}$ recognition through As-S interaction..$^{48,50,51}$ In addition, the $\mathrm{p} K_{\mathrm{a}}$ value of the thiol groups in DTT is typically $\sim 9.2$, and thiolated groups possess a negative charge (from -S-). Considering these points, interactions such as ion-hydrogen bonding interactions and bipolar interactions can account for the maximum responses obtained at the $\mathrm{pH}$ value of 8.5. ${ }^{51}$ Therefore, to adjust the $\mathrm{pH}$ value of the solution in the proposed kit, $45 \mu \mathrm{L}$ of buffer solution was stored in Reservoir 2.

Corresponding experiments were performed to investigate the effect of $\mathrm{pH}$ on the colorimetric response of the proposed kit in the absence and presence of $\mathrm{Hg}^{2+}$ ions in the $\mathrm{pH}$ range from 4.0 to 11.5 at a six-minute time interval. In the absence of $\mathrm{Hg}^{2+}$ ions, it was observed that with an increase in $\mathrm{pH}$ higher than 6.5 , the signal intensities exhibited no change, whereas under this $\mathrm{pH}$ value, GNPs were aggregated in the absence of $\mathrm{Hg}^{2+}$ ions. This can be explained by the fact that in acidic media, the $\mathrm{pH}$ values are below the GNP isoelectric point and thus, the species are in the neutral form, resulting in their aggregation. In addition, in the presence of $\mathrm{Hg}^{2+}$ ions, by increasing the $\mathrm{pH}$ value of the solution from 4.0 to 6.0, the intensities increased until the $\mathrm{pH}$ reached 6.0 for the entire reaction time. Then, at $\mathrm{pH}$ values from 6 to 7.0, the intensities decreased dramatically. This phenomenon is certainly caused by the aggregation of GNPs, which is induced by $\mathrm{Hg}^{2+}$ ions $\left(20 \mu \mathrm{g} \mathrm{L}^{-1}\right)$. Next, a gradual increase in intensities was observed as the $\mathrm{pH}$ increased from 7.0 to 9.5 in the 6 minute reaction time and became constant at 


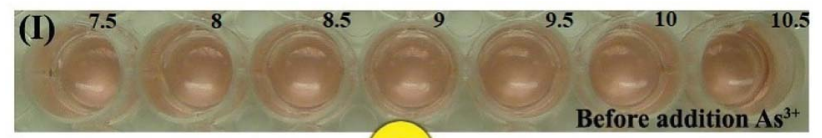

a

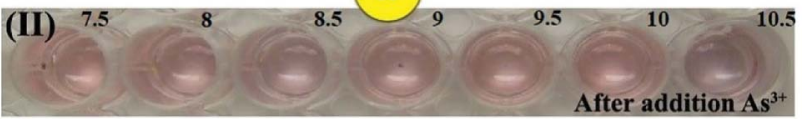

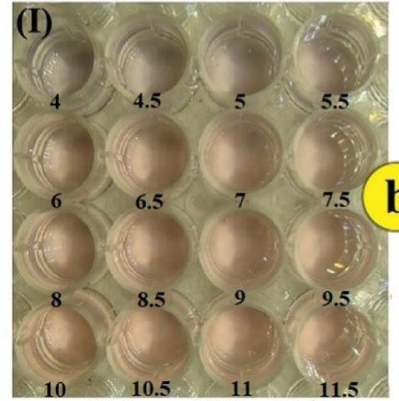

Before addition $\mathrm{Hg}^{2+}$

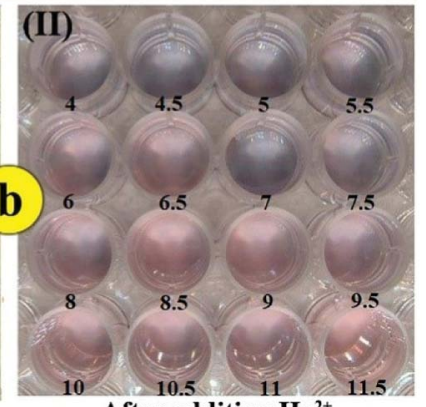

After addition $\mathrm{Hg}^{2+}$
Fig. 3 Effect of $\mathrm{pH}$ on the colorimetric response of (a) (I) GNPs-DTT and (II) GNPs-DTT-PCDA-As ${ }^{3+}$ ions in the range of 7.5 to 10.5 (DDT concentration; time: 8 minutes; volume of GNPs: $300 \mu \mathrm{L}$, and volume of water: $60 \mu \mathrm{L}$ ). (b) Colorimetric response of (I) GNPs-Lys and (II) GNPs-Lys- $\mathrm{Hg}^{2+}$ (Lys concentration: $5 \mathrm{mM}$; time: 6 minutes; volume of GNPs: $200 \mu \mathrm{L}$, and volume of water: $380 \mu \mathrm{L}$ ).

higher $\mathrm{pH}$ values up to 11.5. When $\mathrm{pH}>\mathrm{pH}_{\mathrm{pzc}}=9.74$, the net charge on the Lys molecules was negative, which hindered their attachment to the GNP surface. ${ }^{52}$ As a result, the $\mathrm{pH}$ value of 7.0 was selected as the optimum value for subsequent studies.

Then, at $\mathrm{pH}$ values of 6 to 7.0, intensities decreased dramatically. This phenomenon is certainly caused by the aggregation of GNPs induced by $\mathrm{Hg}^{2+}$ ions $\left(20 \mu \mathrm{g} \mathrm{L}^{-1}\right)$. Next, a gradual increase in intensities was observed as the $\mathrm{pH}$ values increased from 7.0 to 9.5 in the 6 minutes of reaction time and became constant at the higher $\mathrm{pH}$ values by 11.5 .

When $\mathrm{pH}>\mathrm{pH}_{\mathrm{pzc}}=9.74$, the net charge on the Lys molecules is negative, hindering the attachment to GNPs surface. ${ }^{52}$ As a result, the $\mathrm{pH}$ value of 7.0 was selected as the optimum one for subsequent studies.

\section{Analytical performance}

Fig. 4 shows the signal intensities obtained from the colorimetric responses of different $\mathrm{Hg}^{2+}$ (a) and $\mathrm{As}^{3+}$ (b) ion concentrations under the optimum conditions. It was found that the intensities changed linearly with the concentration of $\mathrm{As}^{3+}$ and $\mathrm{Hg}^{2+}$ ions in the range from $710 \mu \mathrm{g} \mathrm{L}^{-1}$ to $1278 \mu \mathrm{g} \mathrm{L}^{-1}$ in 8 minutes and 10.77 to $53.86 \mu \mathrm{g} \mathrm{L}^{-1}$ in 6 minutes (based on a visible change), respectively, according to the following equations:

$$
\begin{aligned}
& I=-0.1005 \mathrm{C} \mathrm{As}^{3+}\left(\mathrm{mg} \mathrm{L}^{-1}\right)+7.0109\left(R^{2}=0.9654(N=7)\right) \\
& I=-0.7584 \mathrm{C} \mathrm{Hg}^{2+}\left(\mathrm{mg} \mathrm{L}^{-1}\right)+6.9472\left(R^{2}=0.9663(N=7)\right)
\end{aligned}
$$

The limits of detection (LOD) for $\mathrm{As}^{3+}$ and $\mathrm{Hg}^{2+}$ ions were calculated to be 224 and $3.4 \mu \mathrm{g} \mathrm{L}^{-1}$, respectively, based on a signal-to-noise ratio of 3 for $\mathrm{As}^{3+}$ and $\mathrm{Hg}^{2+}$ ions.
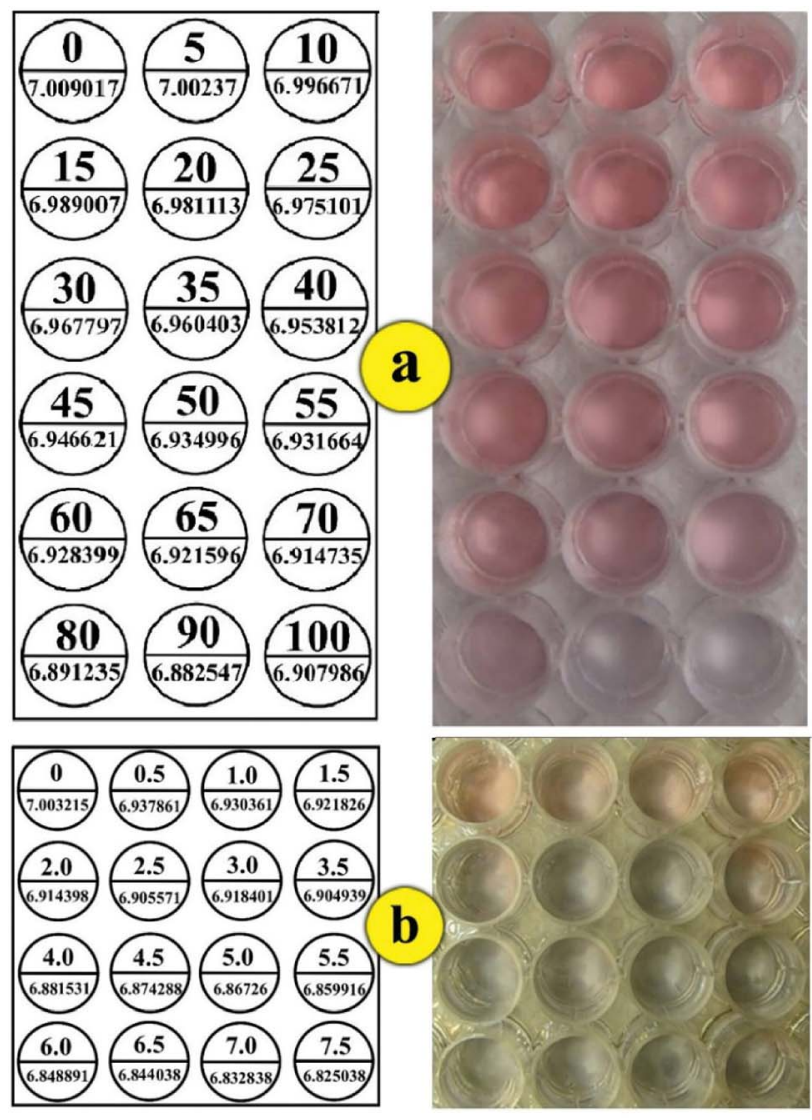

Fig. 4 Colorimetric responses of various concentrations of (a) $\mathrm{As}^{3+}$ and (b) $\mathrm{Hg}^{2+}$ ions; down to up: $0,10.772,21.543,32.315,43.087$, 53.858, 64.63, 75.402, 86.173, 96.945, 107.717, 118.488, 129.26, 140.031, 150.803, $161.575 \mu \mathrm{g} \mathrm{L}^{-1}$ for $\mathrm{As}^{3+}(\mathrm{pH}: 8.5$; time: 8 minutes; volume of GNPs: $300 \mu \mathrm{L}$, and volume of water: $60 \mu \mathrm{L}$ ) and down to up: $0,71,142,213,284,355,426,497,568,639,710,781,852,923,994$, $1136,1278,1420 \mu \mathrm{g} \mathrm{L}^{-1}$ for $\mathrm{Hg}^{2+}$ ( $\mathrm{pH}$ : 7.0; time: 6 minutes; volume of GNPs: $200 \mu \mathrm{L}$, and volume of water: $380 \mu \mathrm{L})$.

In addition, the robustness of the sensor response was evaluated for the storage of the devices for different periods after the addition of the reagents to the PDMS platform. Good stability was observed for the colorimetric responses throughout a period of four weeks (Fig. S4 $\dagger$ ). These characteristics provide an opportunity to fabricate a sensor beforehand for on-site application.

\section{Selectivity of the colorimetric assay}

To evaluate the selectivity of this method for the determination of $\mathrm{As}^{3+}$, the influence of potential interfering ions was investigated at different concentrations in a $20 \mathrm{~min}$ reaction time. When the surface was modified with DTT, the assay showed no responses toward $\mathrm{Pb}^{2+}, \mathrm{Al}^{3+}, \mathrm{K}^{+}, \mathrm{Cd}^{2+}$ and $\mathrm{Sn}^{2+}$ ions at a 200 -fold concentration of $\mathrm{As}^{3+}$ ions $\left(710 \mu \mathrm{g} \mathrm{L}^{-1}\right)$. It should be mentioned that the stability constant of the $\mathrm{As}^{3+}$-DTT complex was about 30 orders of magnitude higher than that of other interfering metal ions. ${ }^{38}$ However, $\mathrm{Ni}^{2+}$ and $\mathrm{Zn}^{2+}$ ions resulted in the aggregation of GNPs at 20- and 30-fold concentrations of $\mathrm{As}^{3+}$ ions $\left(710 \mu \mathrm{g} \mathrm{L}^{-1}\right)$ after $20 \mathrm{~min}$ reaction time, respectively, which 

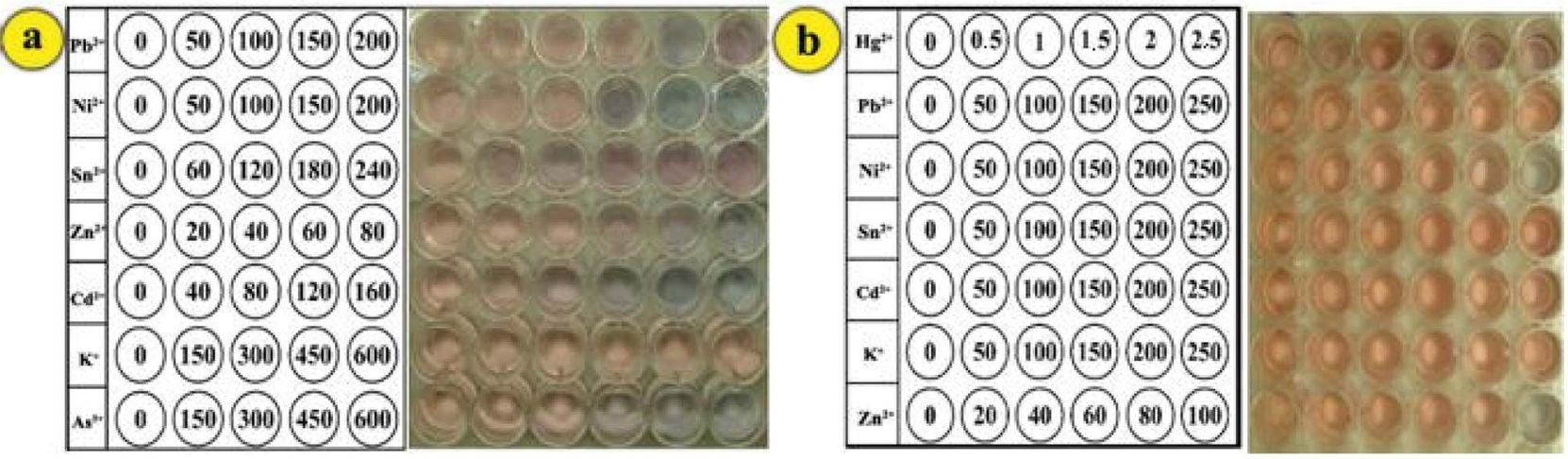

Fig. 5 Effect of potential interfering ions on the colorimetric response of (a) GNPs-DTT (pH: 8.5; time: 8 minutes; volume of GNPs: $300 \mu \mathrm{L}$ ), and volume of water: $60 \mu \mathrm{L}$ and (b) colorimetric response of GNPs-Lys and (pH: 8.5; time: 6 minutes; volume of GNPs: $200 \mu \mathrm{L}$, and volume of water: $380 \mu \mathrm{L})$; ions: $\mathrm{Ni}^{2+}, \mathrm{Pb}^{2+}, \mathrm{Hg}^{2+}, \mathrm{Zn}^{2+}, \mathrm{K}^{+}, \mathrm{Cd}^{2+}, \mathrm{Sn}^{2+}$, and $\mathrm{As}^{3+}$.

indicated that they exhibited no interference due to the response time of assay and lack of high concentrations of these interfering ions in real samples. High concentrations of $\mathrm{Hg}^{2+}$ ions interfered with the $\mathrm{As}^{3+}$ signal. The selectivity of the assay toward $\mathrm{As}^{3+}$ ions was significantly improved by the addition of PCDA due to its higher affinity for $\mathrm{As}^{3+}$ than that for mercury ions. Since the colorimetric signals may be affected by the concentration of PCDA along with its function to improve the selectivity of the sensor, the concentration effect of PCDA was studied on the colorimetric signal of DTT-GNPs in different concentrations of PCDA for 20 min. The results showed that the selectivity of the colorimetric responses increased as the concentration of PCDA increased from 1 to $1.5 \mathrm{mM}$, whereas at concentrations higher than $1.5 \mathrm{mM}$, the signal intensities remained constant in a 4 min period (Fig. 5a).

Furthermore, to determine the selectivity of the colorimetric assay against $\mathrm{Hg}^{2+}, 7$ heavy metal ions $\left(\mathrm{Ni}^{2+}, \mathrm{Pb}^{2+}, \mathrm{Zn}^{2+}, \mathrm{As}^{3+}\right.$, $\mathrm{Al}^{3+}, \mathrm{K}^{+}$, and $\mathrm{Cd}^{2+}$ ) were tested in the assay. Fig. $4 \mathrm{~b}$ shows the response of the colorimetric assay against competing metal ions $\left(2 \mathrm{mg} \mathrm{L}^{-1}\right)$ and $\mathrm{Hg}^{2+}$ ions $\left(20 \mu \mathrm{g} \mathrm{L}^{-1}\right)$ in the presence of lysine. The response of the assay was affected by $\mathrm{As}^{3+}, \mathrm{Sn}^{2+}$ and $\mathrm{Pb}^{2+}$ ions at concentrations higher than 50 fold of that of $\mathrm{Hg}^{2+}$ only after $20 \mathrm{~min}$, whereas the response indicated no change for $\mathrm{K}^{+}$ ions for the whole period. In our experiments, the addition of $\mathrm{Zn}^{2+}$ and $\mathrm{Cd}^{2+}$ ions to the system led to a color change at 20 -fold concentration after 15 and $18 \mathrm{~min}$, respectively. These results showed that interfering ions only slightly affect colorimetric responses at the desired time and concentration range, which indicated the excellent selectivity of the colorimetric kit for $\mathrm{Hg}^{2+}$ and $\mathrm{As}^{3+}$ ion determination (Fig. 5b).

\section{Real sample analysis}

To test the practical applications of the proposed kit, it was used to determine and recover $\mathrm{As}^{3+}$ and $\mathrm{Hg}^{2+}$ ions in spiked water samples. For this purpose, drinking water samples were used without any filtration or preparation. The water samples were spiked with 10.772, 21.543, and $32.315 \mu \mathrm{g} \mathrm{L} \mathrm{L}^{-1}$ concentrations of $\mathrm{Hg}^{2+}$ and 710,852 , and $923 \mu \mathrm{g} \mathrm{L} \mathrm{L}^{-1}$ concentrations of $\mathrm{As}^{3+}$; then, $50 \mu \mathrm{L}$ aliquots of these final solutions were dropped on the
Table 1 The results for the detection of $\mathrm{As}^{3+}$ and $\mathrm{Hg}^{2+}$ ions in real water samples

\begin{tabular}{llllll}
\hline Ions & Water samples & $\begin{array}{l}\text { Spiked } \\
\left(\mu \mathrm{g} \mathrm{L}^{-1}\right)\end{array}$ & $\begin{array}{l}\text { Found } \\
\left(\mu \mathrm{g} \mathrm{L}^{-1}\right)\end{array}$ & $\begin{array}{l}\text { Recovery } \\
(\%)\end{array}$ & $(\mathrm{RSD} \%)$ \\
\hline $\mathrm{Hg}^{2+}$ & Drinking & 10.77 & 10.25 & 95.20 & 5.10 \\
& water & 21.54 & 21.02 & 97.60 & 4.08 \\
& & 32.31 & 34.21 & 94.44 & 4.92 \\
$\mathrm{As}^{3+}$ & Drinking & 710 & 688.98 & 97.04 & 3.95 \\
& water & 852 & 828.99 & 97.30 & 5.39 \\
& & 923 & 909.61 & 98.55 & 4.68 \\
$\mathrm{Hg}^{2+}$ & Rain water & 10.77 & 10.16 & 94.30 & 5.58 \\
& & 21.54 & 20.45 & 94.97 & 4.38 \\
$\mathrm{As}^{3+}$ & Rain water & 32.31 & 30.82 & 95.39 & 5.84 \\
& & 710 & 671.09 & 94.82 & 5.49 \\
& & 852 & 813.23 & 95.45 & 6.05 \\
& & 923 & 870.94 & 94.36 & 5.73 \\
\hline
\end{tabular}

Table 2 A comparison of the analytical performances of different colorimetric methods for the determination of $\mathrm{As}^{3+}$ and $\mathrm{Hg}^{2+}$ ions

\begin{tabular}{|c|c|c|c|c|}
\hline Colorimetric sensor & $\operatorname{LOD}\left(\mu \mathrm{g} \mathrm{L}{ }^{-1}\right)$ & Selectivity & $\begin{array}{l}\text { Time } \\
(\mathrm{min})\end{array}$ & Reference \\
\hline Dithia-diaza/GNPs & 7.0 & $\mathrm{Hg}^{2+}$ & 10 & 53 \\
\hline $\begin{array}{l}\text { Thymine- } \mathrm{Hg}^{2+} \\
\text {-thymine/GNPs }\end{array}$ & 10 & $\mathrm{Hg}^{2+}$ & 40 & 54 \\
\hline Urine/GNPs & 20 & $\mathrm{Hg}^{2+}$ & 15 & 55 \\
\hline As(III)/aptamer/GNPs & 5.3 & $\mathrm{As}^{3+}$ & - & 19 \\
\hline As(III)/aptamer/GNPs & 1.26 & $\mathrm{As}^{3+}$ & 30 & 19 \\
\hline DTT/GSH/Cys-GNPs & 0.003 & $\begin{array}{l}\mathrm{As}^{3+} \\
\text { and } \mathrm{As}^{5+}\end{array}$ & - & 38 \\
\hline Laurel sulfate/GNPs & 5.0 & $\mathrm{As}^{3+}$ & 5.0 & 56 \\
\hline $\begin{array}{l}\text { DTT-PCDA/GNPs } \\
\text { and lysine/GNPs }\end{array}$ & $\begin{array}{l}224\left(\mathrm{As}^{3+}\right) \\
\text { and } 3.4\left(\mathrm{Hg}^{2+}\right)\end{array}$ & $\begin{array}{l}\mathrm{As}^{3+} \\
\text { and } \mathrm{Hg}^{2+}\end{array}$ & 8.0 & This work \\
\hline
\end{tabular}

sample well of the microfluidic device, and $\mathrm{As}^{3+}$ and $\mathrm{Hg}^{2+}$ ion recoveries were obtained by colorimetric measurements using the proposed kit. As can be seen in Table 1, the recoveries obtained varied within the range from $94.44 \%$ to $98.55 \%$. Hence, it can be considered that the matrix of the water samples does not 
interfere significantly in the determination of $\mathrm{As}^{3+}$ and $\mathrm{Hg}^{2+}$ ions using the proposed sensor.

In Table 2, some of the response characteristics obtained for the simultaneous determination of $\mathrm{As}^{3+}$ and $\mathrm{Hg}^{2+}$ in this study are compared with those previously reported in the field of colorimetric sensors. As can be seen, the responses of the proposed kit are comparable with those of previously reported sensors. More importantly, there is no report on the simultaneous colorimetric determination of $\mathrm{As}^{3+}$ and $\mathrm{Hg}^{2+}$ ions by a microfluidic kit.

\section{Conclusions}

Wastewater pollution in industrial areas is one of the most important environmental threats in the future. In the present study, a new smartphone-based platform based on GNPs-DTTPCDA and GNPs-Lys and placed in the reservoirs of a microfluidic kit was developed for the simultaneous detection of $\mathrm{As}^{3+}$ and $\mathrm{Hg}^{2+}$ ions. The microfluidic kit was fabricated using a PDMS substrate and a new multistep method. Also, HMD as a new app (RGB reader) was developed for Android smartphones to quantify the colorimetric results. In the proposed kit, the effects of various parameters including $\mathrm{pH}$ of the solution, the concentration of ligands, and response time for the detection of the target analytes were studied and optimized.

Our goal was the development of a simple, rapid, low-cost kit for the in-field detection of $\mathrm{As}^{3+}$ and $\mathrm{Hg}^{2+}$ in contaminated water sources. This constructed kit can be used for environmental monitoring of contaminants in wastewater samples. The fabricated kit can sense these toxic heavy metals in the field to improve the monitoring of water and wastewater sources. This strategy can provide a simultaneous and simple method for the determination of $\mathrm{As}^{3+}$ and $\mathrm{Hg}^{2+}$ ions with real-time visualization of a low concentration of target ions within 8 minutes. However, LODs of the kit for target analytes are still a great challenge. The LODs are higher than the maximum concentrations permitted by the EPA in river water or other samples. Therefore, detailed studies are needed to improve the LODs and linear ranges of the developed kit, which are underway.

\section{Conflicts of interest}

There are no conflicts to declare.

\section{Acknowledgements}

Financial support from the Research Ministry of Baqiyatallah University of Medical Sciences is gratefully appreciated.

\section{References}

1 M. Mulvihill, A. Tao, K. Benjauthrit, J. Arnold and P. Yang, Angew. Chem., 2008, 120, 6556-6560.

2 P. Nath, R. K. Arun and N. Chanda, RSC Adv., 2014, 4, 5955859561.
3 A. Chaudhary, C. Dwivedi, M. Chawla, A. Gupta and C. K. Nandi, J. Mater. Chem. C, 2015, 3, 6962-6965.

4 G. Sener, L. Uzun and A. Denizli, Anal. Chem., 2013, 86, 514520.

5 D. Sanchez-Rodas, W. Corns, B. Chen and P. Stockwell, J. Anal. At. Spectrom., 2010, 25, 933-946.

6 L. Rahman, W. Corns, D. Bryce and P. Stockwell, Talanta, 2000, 52, 833-843.

7 B. Kumar Jena and C. Retna Raj, Anal. Chem., 2008, 80, 48364844.

8 A. Howard and M. Arbab-Zavar, Analyst, 1981, 106, 213-220.

9 H. Bagheri, A. Afkhami, H. Khoshsafar, M. Rezaei, S. J. Sabounchi and M. Sarlakifar, Anal. Chim. Acta, 2015, 870, 56-66.

10 M. Zaib, M. M. Athar, A. Saeed and U. Farooq, Biosens. Bioelectron., 2015, 74, 895-908.

$11 \mathrm{~J}$. L. Gómez-Ariza, D. Sánchez-Rodas, I. Giráldez and E. Morales, Talanta, 2000, 51, 257-268.

12 J. L. Gómez-Ariza, F. Lorenzo and T. García-Barrera, Anal. Bioanal. Chem., 2005, 382, 485-492.

13 A. K. Yetisen, M. S. Akram and C. R. Lowe, Lab Chip, 2013, 13, 2210-2251.

14 X. Xuan, M. F. Hossain and J. Y. Park, Sci. Rep., 2016, 6, 33125.

15 W. Chen, X. Fang, H. Li, H. Cao and J. Kong, Sci. Rep., 2016, 6, 31948 .

16 S. K. Ludwig, C. Tokarski, S. N. Lang, L. A. van Ginkel, H. Zhu, A. Ozcan and M. W. Nielen, PLoS One, 2015, 10, e0134360.

17 L. Guan, J. Tian, R. Cao, M. Li, Z. Cai and W. Shen, Anal. Chem., 2014, 86, 11362-11367.

18 Y. Liu, Q. Liu, S. Chen, F. Cheng, H. Wang and W. Peng, Sci. Rep., 2015, 5, 12864.

19 Y. Wu, S. Zhan, F. Wang, L. He, W. Zhi and P. Zhou, Chem. Commun., 2012, 48, 4459-4461.

20 R. P. Liang, Z. X. Wang, L. Zhang and J. D. Qiu, Chem.-Eur. J., 2013, 19, 5029-5033.

21 J. S. Lee, M. S. Han and C. A. Mirkin, Angew. Chem., 2007, 119, 4171-4174.

22 X. Xu, J. Wang, K. Jiao and X. Yang, Biosens. Bioelectron., 2009, 24, 3153-3158.

23 Z. Wang, J. H. Lee and Y. Lu, Adv. Mater., 2008, 20, 32633267.

24 J. Xin, L. Miao, S. Chen and A. Wu, Anal. Methods, 2012, 4, 1259-1264.

25 Y. Guo, Z. Wang, W. Qu, H. Shao and X. Jiang, Biosens. Bioelectron., 2011, 26, 4064-4069.

26 G. H. Wu, C. Dong, Y. L. Li, Z. Q. Wang, Y. X. Gao, Z. Y. Shen and A. U. Wu, RSC Adv., 2015, 5, 20595-20602.

27 C. Dong, G. H. Wu, Z. Q. Wang, W. Z. Ren, Y. J. Zhang, Z. Y. Shen, T. H. Li and A. G. Wu, Dalton Trans., 2016, 45, 8347-8354.

28 W. W. Chen, F. J. Cao, W. S. Zheng, Y. Tian, Y. L. Xianyu, P. Xu, W. Zhang, Z. Wang, K. Deng and X. Y. Jiang, Nanoscale, 2015, 7, 2042-2049. 
29 C. Dong, Z. Q. Wang, Y. J. Zhang, X. H. Ma, M. Z. Lqbal, L. J. Miao, Z. W. Zhou, Z. Y. Shen and A. G. Wu, ACS Sens., 2017, 2, 1152-1159.

30 T. Lou, L. Chen, Z. Chen, Y. Wang, L. Chen and J. Li, ACS Appl. Mater. Interfaces, 2011, 3, 4215-4220.

31 Y. Date, S. Terakado, K. Sasaki, A. Aota, N. Matsumoto, H. Shiku, K. Ino, Y. Watanabe, T. Matsue and N. Ohmura, Biosens. Bioelectron., 2012, 33, 106-112.

32 I.-H. Chang, J. J. Tulock, J. Liu, W.-S. Kim, D. M. Cannon, Y. Lu, P. W. Bohn, J. V. Sweedler and D. M. Cropek, Environ. Sci. Technol., 2005, 39, 3756-3761.

33 M. Yuan, Y. Zhu, X. Lou, C. Chen, G. Wei, M. Lan and J. Zhao, Biosens. Bioelectron., 2012, 31, 330-336.

34 L. Zhao, T. Wu, J.-P. Lefèvre, I. Leray and J. A. Delaire, Lab Chip, 2009, 9, 2818-2823.

35 W. Som-Aum, J. Threeprom, H. Li and J.-M. Lin, Talanta, 2007, 71, 2062-2068.

36 W. Haiss, N. T. Thanh, J. Aveyard and D. G. Fernig, Anal. Chem., 2007, 79, 4215-4221.

37 D. M. Cate, J. A. Adkins, J. Mettakoonpitak and C. S. Henry, Anal. Chem., 2015, 87, 19-41.

38 J. R. Kalluri, T. Arbneshi, S. Afrin Khan, A. Neely, P. Candice, B. Varisli, M. Washington, S. McAfee, B. Robinson, S. Banerjee, A. K. Singh, D. Senapati and P. Chandra Ray, Angew. Chem., 2009, 121, 9848-9851.

39 F. M. White, Fluid Mechanics, McGraw-Hill Book Company, Boston, 5th edn, 2003.

40 V. Faustino, S. O. Catarino, R. Lima and G. Minas, J. Appl. Biomech., 2016, 49, 2280-2292.

41 B. Xu, K. Ooti, N. Wong and W. Choi, Int. Commun. Heat Mass Transfer, 2000, 27, 1165-1176.
42 G. Hetsroni, A. Mosyak, E. Pogrebnyak and L. Yarin, Int. J. Heat Mass Transfer, 2005, 48, 1982-1998.

43 J. Koo and C. Kleinstreuer, J. Micromech. Microeng., 2003, 13, 568.

44 C.-Y. Lee, W.-T. Wang, C.-C. Liu and L.-M. Fu, Chem. Eng. J., 2016, 288, 146-160.

45 E. E. Kerre and M. Nachtegael, Fuzzy techniques in image processing, Physica, 2013.

46 S. M. Smith and J. M. Brady, Int. J. Comput. Vis., 1997, 23, 4578.

47 W. Burger, M. J. Burge, M. J. Burge and M. J. Burge, Principles of digital image processing, Springer, 2009.

48 M. Bissen and F. H. Frimmel, Clean: Soil, Air, Water, 2003, 31, 9-18.

49 R. P. Liang, Z. X. Wang, L. Zhang and J. D. Qiu, Chem.-Eur. J., 2013, 19, 5029-5033.

50 J. H. Luong, E. Lam and K. B. Male, Anal. Methods, 2014, 6, 6157-6169.

51 Q. Zhang, F. Liu, K. T. Nguyen, X. Ma, X. Wang, B. Xing and Y. Zhao, Adv. Funct. Mater., 2012, 22, 5144-5156.

52 Y. Chen, L. Yao, Y. Deng, D. Pan, E. Ogabiela, J. Cao, S. B. Adeloju and W. Chen, Microchim. Acta, 2015, 182, 2147-2154.

53 W. Chansuvarn and A. Imyim, Microchim. Acta, 2012, 176, 57-64.

54 G.-H. Chen, W.-Y. Chen, Y.-C. Yen, C.-W. Wang, H.-T. Chang and C.-F. Chen, Anal. Chem., 2014, 86, 6843-6849.

55 J. Du, B. Zhu and X. Chen, Small, 2013, 9, 4104-4111.

56 K. Shrivas, R. Shankar and K. Dewangan, Sens. Actuators, B, 2015, 220, 1376-1383. 